\title{
STUDY ON MORPHOLOGICAL CHANGES IN THE GALL BLADDER MUCOSA ASSOCIATED WITH CHOLELITHIASIS.
}

1. MBBS, M.Phil (Anatomy) Lecturer Anatomy

Bilawal Medical College, Liaquat University of Medical \& Health Sciences, Jamshoro.

2. MBBS, M.Phil (Anatomy) Associate Professor Anatomy Bilawal Medical College, Liaquat University of

Medical \& Health Sciences, Jamshoro.

3. MBBS, M.Phil (Anatomy) Assistant Professor Anatomy Bilawal Medical College, Liaquat University of Medical \& Health Sciences, Jamshoro.

4. MBBS, M.Phil (Anatomy) Lecturer Anatomy

Peoples University of Medical \& Health Sciences for

Women Shaheed Benazirabad Nawabshah.

5. MBBS, M.Phil (Pharmacology), Ph.D Scholar Senior Demonstrator Pharmacology Bolan University of Medical \& Health Sciences (BUMHS), Quetta

6. MBBS, M.Phil (Physiology) Lecturer Physiology Peoples University of Medical \& Health Sciences for Women Shaheed Benazirabad.

Correspondence Address:

Dr. Gulshad Wagan

MBBS, M.Phil (Anatomy)

Department of Anatomy

Bilawal Medical College, Liaquat

University of

Medical \& Health Sciences, Jamshoro.

farooq346@gmail.com

Article received on:

12/01/2019

Accepted for publication:

03/12/2019

\section{INTRODUCTION}

Gall stone is the hepatobiliary system's acute recurrent disease. The stone growth is known to be accountable for impaired cholesterol, bile acids and bilirubin.

Cholelithiasis is the world's main cause of morbidity and death. Due to the enhanced intake of wealthy calories and fatty diet and increasing alcoholic consumption, the prevalence of cholecystitis and colelithiasis has risen globally over the previous couple of centuries. ${ }^{2,3}$ Rehnaz Shaikh ${ }^{6}$

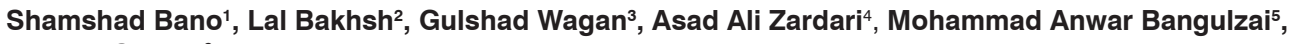

RTCT... Cholelithiasis is known to produce diverse histopathological changes in the gallbladder mucosa. Objectives: To observe the morphological changes in the gall bladder mucosa associated with cholelithiasis. Study Design: Descriptive Cross Sectional study. Setting: Department of Anatomy, Jamshoro with collaboration of Department of Pathology, LUMHS, Jamshoro. Period: April 2016 to October 2016. Material and Methods: All the cases after diagnosis of cholelithiasis with all age groups (20 to 50 years) in male and female were included. Gallstones were assessed for various parameters, i.e., number, size, and morphological type. Gallbladder mucosa was subjected to histopathological examination. Sections of the body, the fundus and the bottom of the gallbladder were drawn. $01 \mathrm{~cm}$ of the body, the body, and the bottom of the gallbladder were drawn from the funduse and (Statistical Package of Social Sciences) version 22.0. Results: Total 87 cases were selected and average age of $49.95 \pm 6.14$ years of male was seen in a gall bladder width and length in the gallbladder and gallbladder length in both sex of P-value 0.07 while male of female average were 41.30añ6.62, age range from 30 to 52 years. Sixty-seven (77.0\%) cases had multiple stones. 29 (33.3 percent) patients had congested the serological layer, while 58 (66.7 percent) were usually impacted. Mucosa hemorrhagic in 22(25.3\%) cases, atrophic in $51(58.6 \%)$ cases and nodular in $4(4.6 \%)$ cases. 36(41.4\%) gall bladders reported normal results, 41(47.1\%), 1(1.1\%), and 3(3.4\%) were identified with Fibrosis, and 2(2.3\%) are found with Fibrosis. Many cases were linked to fibrosis, dysplasia, and hyperplasia, compared to single calculus ( $P$ value 0.048). There was no substantial difference between normal and thickened gall bladders in the microscopic tests ( $P$ value 0.26 ). Fibrosis, dysprasia and hyperplasia are correlated mainly with internal mucus detections ( $P$ value 0.002$)$. Hemorrhagic mucous membranes are found mainly. Conclusion: Hemorrhagic and fibrotic changes were the most common mucosal findings, and significantly associated with multiple cholelithiasis.

Key words: $\quad$ Gall Stone, Gall Bladder Mucosa, Morphological Findings.

Article Citation: Bano S, Bakhsh L, Wagan G, Zardari AA, Bangulzai MA, Shaikh R. Study on morphological changes in the gall bladder mucosa associated with cholelithiasis. Professional Med J 2020; 27(8):1753-1762.

DOI: 10.29309/TPMJ/2020.27.08.4343 
been discovered to be $9.03 \%(95 \% \mathrm{Cl}, 8.6 \%-$ $9.4 \%)$. Women are 3.3 times more likely to create Gallstones than men are. ${ }^{5}$

Of the 400 patients affected by gallstones, 320 (80 percent) had gallstones, Samra et al. ${ }^{7}$ reported. ${ }^{7}$

Gallbladder stones are documented in gallbladder mucosal histopathology to generate acute inflammation, chronic inflammation, glandular hyperplasia, granulomatous inflammation, cholisterose, dysplasia and carcinoma. The chemical composition of gallstones differs.

Gallbladder mucin is one of the factors in gallstone formation. ${ }^{8-10}$ It is also one of the predisposing causes of gallbladder cancer.

There are three types of gall bladder stones:

1. Cholesterol stones

2. Pigment (brown/black) stones

3. Mixed stones

In Pakistan the gall gland stones have substantially risen because of the use of a strong calorie diet wealthy in sugar but low in fibre content, and in Asia 80 percent is colored stones. ${ }^{11}$

Mixing stone contains 51-99\% sheer cholesterol plus calcium salt admixture, bile acid, and phospholipids, bile pigments. Cholesterol gall stone represents $80-90 \%$ all stones.

Concentration of phospholipids and bile acids in bile and the type of phospholipids and bile acids is responsible for keeping cholesterol in solution. . $^{41}$

Stone formation: If bile is over-saturated with low concentrations of cholesterol and/or bile acids, volatile lamellar phospholipids create vesicles of cholesterol that can lead to the development of nuclei and stones.

The factors responsible for gall stones formation are as follow:

Obesity, high calorie diets \& certain drugs can increase the secretion of cholesterol, supersaturate the bile and increase the risk of stone formation.

Abnormal emptying of gall bladder can possibly encourage accumulation of nucleated cholesterol crystals therefore remaining gallstones without eliminating gallbladder results in gall stone reappearance. Pigment stones are defined as the gall stones which contain cholesterol below $30 \%$ and two types of pigment stones usually exist, the brown and black stones. ${ }^{12}$ The aim of this study was to observe morphological changes in gall bladder mucosa associated with cholelithiasis

\section{MATERIAL \& METHODS}

This descriptive cross sectional study was conducted on 87 samples at department of anatomy, LUMHS, Jamshoro from April 2016 to October 2016. All the cases after diagnosis of cholelithiasis with age range (20 to 50 years) in male and female were included. While gall bladder diagnosed with carcinoma of gall bladder were excluded.

Once the topics consented, data was gathered. Prior departmental consent was acquired for the compilation of specimens from operating theater by the Departments of Operation and Minimal Invasive Surgery. Permission from the President of the Pathology Department was received

Before gathering information, permission was acquired from the Research Ethical Committee (REC). Gall bladder was dismissed as wastage after cholecystectomy, when the histopathological sample was taken. Record / report confidentiality has been preserved. The record / reports were kept confidential and information were used solely for study purposes.

Gall bladders were collected from Operation Theaters (O.T 10 Liaquat University Medical and Health Science Jamshoro and O.T of minimal invasive surgical centre LUMHS Jamshoro) and preserved in plastic jars containing $10 \%$ formalin for fixation.

Gross morphological study of gall bladders was conducted at the Department of pathology LUMHS Jamshoro. $01 \mathrm{~cm}$ pieces were taken 
from fundus, body and the neck of gall bladder and were processed for histological studies. Histopathological changes were observed following classical heamatoxylin and eosine $(\mathrm{H}$ and E) stain and these changes were noted on the prescribed proforma.

\section{Gross Examination}

All gallbladders have been evaluated with the assistance of centimeter tape after rinsing with flowing cassette water and drying with blotting paper.

Gross exam was performed for all defects, $1 \mathrm{~cm}$ parts of the fundus, head and throat were drawn from a gallbladder and handled for histology research following gross examination.

The gallbladder components were selected randomly and stored for subsequent processing as 10 percent formalin solution. The jars have a code number + the record number of the hospital.

The gross examination of samples was carried out in the Department of Pathology, LUMHS, Jamshoro."

\section{Histological Examination}

Paraffin tissue processing for sectioning A number of procedures from dehydration and clearing through to wax impregnations have been carried out before the segment is rendered set. Total processing time was 24 hours."

\section{Dehydration}

Dehydration was achieved by putting the tissues at rising alcohol levels between $70 \%$ and $100 \%$.

Samples were kept in $80 \%$ alcohol for 1 hour. Then $3 \mathrm{X}$ (3 times) in 95\% alcohol for 2 hours. Samples were then kept in $100 \%$ ethanol overnight."

Clearing

After all the water has been removed from tissue samples, alcohol was removed using xylene to mix wax into the samples. For 1 hour each sample washed 3 times in xylene.
Wax impregnation

The samples were then passed on to two paraffin wax changements until they were thoroughly impregnated after all clearing. The temperature was rigorously checked at this point.

Tissue was divided into rotary microtomes at $5 \mu \mathrm{m}$ and diaphragm slides were prepared with glass slides covered by the APES (3-aminopropyltriethoxysilan) plating.

Haematoxylin and Eosin staining of tissue slides After all slides are ready, xylene- 1 is spent 10 minutes and xylene-2 is spent another 10 minutes. Slides were placed in $100 \%, 95 \%, 80 \%$, and 5 minutes each with $70 \%$ alcohol after clearing.

The slides were hydrated and put 5-10 minutes into the Harris Haematoxylin solution. Hematoxylin has been removed and fabrics washed with tap water.

Tissues in acid alcohol were differentiated to remove excess stain in a saturated lithium carbonate solution before the nuclei were bluted. The tissues were washed again and placed in 1 percent eosin for about 1-2 minutes.

Excessive stain was removed and tap water slides washed. The tissues were finally dried by increasing alcohol levels and cleaned for 5 minutes with xylene.

The diaphragms were then placed in a dry state, and covered in DPX (a mixture of distyrene, plasticiser and phosphate) and xylene. The ready slides with $10 \mathrm{HPF}$ (high-power fields) were examined under a light microsope.

SPSS version 20 evaluated all of the data. For numerical variables, mean and standard deviation are calculated. For qualitative variables, rate and percentage are calculated. Applied Chi-Square and found to be important the $p$-value $<0.05$. 


\section{RESULTS}

Table-I allocated the clients by sex and the bulk of clients were women, 65 (74.7\%), whereas men were 22 (25.3\%). Table-I Male mean age was discovered to be $40.95+6.14$ years of era, varying between 31 and 50 years, while woman mean age was $41.30+6.62$, ranging between 30 and 52 years. Table-II In both genders P-value 0.07 , no important differences were identified in gallbladder thickness and length.

$31.04 \%$ of instances were symptomatic, whereas $68,96 \%$ were asymptomatic, according to the clinical description.

Gallbladder colors show that the majority of cases in the case were green $(5 \%) / 67.8 \%$ and gray $(14 / 16.1 \%)$ followed by brown, brown, brown green, greenish velvety, white greenish and light green with $2.3 \%, 1.1 \%, 6.9 \%, 1.1 \%$, and $1.1 \%$ respectively. Table-I. The gall color was discovered as; purple was discovered in $42(48.3$ percent), purple was discovered in $10(11.5$ percent), while the color of 16 (18.4 percent) of caps was black and in 19 (21.8 percent) of the instances the color was purple. Table-I

The internal Gall bladder differences are shown in Table-l. 29 (33.3\%) patients had a serosal surface congested, while $58(66.7 \%)$ were regular. In $10(11.49 \%)$ instances, mucosa was normal, in $22(25.3 \%)$ instances it was hemorrhagic, in $51(58.6 \%)$ it was inactive and in $4(4.59 \%)$ it became nodular.

The most prevalent in 41 (47.1 percent) patients, accompanied by dysplasia in 1 (1.1 percent), inflamed 4 patients ( 4.59 percent) and hyperplasia (2.3 percent) were 36 (41,4 percent) patients with standard microscopic results. Table-l. When comparing the length of the gall bladder to microscopic results, most fibrosis was linked with 7-9 cm, while 4-6 cm were associated with dysplasia and hyperplasia. Table-III. Dysplasia and hyperplasia were correlated with several instances in comparison to one calculus mainly in the results of our research. P 0.048 value. Table-III

There was no important distinction between

ordinary and dense wall-gallbladder contrast and cholithiasis in the microscopic results. $P$ is 0.26 Table-III. Comparisons of internal mucosal results have been substantially correlated with fibrosis, dysplasia and hyperplasia with the hemorrhagic results (p-value 0,002). Table-III. Figure-1 showed different histological changes in the gall bladder associated with gall stones.

\begin{tabular}{|c|c|c|}
\hline Sex & Frequency & Percent \\
\hline $\begin{array}{l}\text { Female } \\
\text { Male }\end{array}$ & $\begin{array}{l}65 \\
22\end{array}$ & $\begin{array}{l}74.7 \% \\
25.3 \%\end{array}$ \\
\hline \multicolumn{3}{|l|}{ Presentation } \\
\hline $\begin{array}{l}\text { Asymptomatic } \\
\text { symptomatic }\end{array}$ & $\begin{array}{l}60 \\
27\end{array}$ & $\begin{array}{l}68.96 \% \\
31.04 \%\end{array}$ \\
\hline \multicolumn{3}{|l|}{ Gall bladder colour } \\
\hline $\begin{array}{l}\text { Brown } \\
\text { Green } \\
\text { Greenish brown } \\
\text { Gray brown } \\
\text { Gray white } \\
\text { Green velvety } \\
\text { Greenish white } \\
\text { Light green }\end{array}$ & $\begin{array}{c}2 \\
59 \\
1 \\
6 \\
14 \\
3 \\
1 \\
1\end{array}$ & $\begin{array}{c}2.3 \% \\
67.8 \% \\
1.1 \% \\
6.9 \% \\
16.1 \% \\
3.4 \% \\
1.1 \% \\
1.1 \%\end{array}$ \\
\hline \multicolumn{3}{|l|}{ No. of Gall Stones } \\
\hline $\begin{array}{l}\text { Multiple } \\
\text { Single }\end{array}$ & $\begin{array}{l}67 \\
20\end{array}$ & $\begin{array}{l}77.0 \% \\
23.0 \%\end{array}$ \\
\hline \multicolumn{3}{|l|}{ Colour of Gall stone } \\
\hline $\begin{array}{l}\text { Brown } \\
\text { Black } \\
\text { Green } \\
\text { Yellow }\end{array}$ & $\begin{array}{l}10 \\
16 \\
19 \\
42\end{array}$ & $\begin{array}{l}11.5 \% \\
18.4 \% \\
21.8 \% \\
48.3 \%\end{array}$ \\
\hline \multicolumn{3}{|l|}{ External variations } \\
\hline $\begin{array}{l}\text { SEROSAL SURFACE } \\
\text { Congested } \\
\text { Normal } \\
\text { WALL } \\
\text { Normal } \\
\text { Thickened } \\
\text { MUCOSA } \\
\text { Normal } \\
\text { Hemorrhagic } \\
\text { Atrophic } \\
\text { Nodular }\end{array}$ & $\begin{array}{l}29 \\
58 \\
\\
64 \\
23 \\
\\
10 \\
22 \\
51 \\
04\end{array}$ & $\begin{array}{c}33.3 \% \\
66.7 \% \\
\\
73.6 \% \\
26.4 \% \\
\\
11.49 \% \\
25.2 \% \\
58.6 \% \\
04.59 \%\end{array}$ \\
\hline \multicolumn{3}{|l|}{ Internal variations } \\
\hline $\begin{array}{l}\text { Normal } \\
\text { Abnormal } \\
\text { Dysplasia } \\
\text { Fibrosis } \\
\text { Inflamed } \\
\text { Hyperplasia }\end{array}$ & $\begin{array}{c}36 \\
3 \\
1 \\
41 \\
4 \\
2\end{array}$ & $\begin{array}{c}41.4 \% \\
3.4 \% \\
1.1 \% \\
47.1 \% \\
4.59 \% \\
2.3 \%\end{array}$ \\
\hline
\end{tabular}




\begin{tabular}{|l|c|c|c|c|}
\hline & \multicolumn{3}{|c|}{ Age, GB length and width } \\
\hline Gender & Mean \pm SD & Minimum & Maximum & P-Value \\
\hline Age & & & 50 & \multirow{2}{*}{0.83} \\
\hline Male & $40.95 \pm 6.14$ & 31 & 52 & \\
\hline female & $41.30 \pm 6.62$ & 30 & & \multirow{2}{*}{0.06} \\
\hline GB length & & & 8.0 & \\
\hline Male & $5.13 \pm 1.46$ & 1.50 & 9.0 & 0.07 \\
\hline Female & $5.84 \pm 1.36$ & 2.0 & 3.0 & 0.07 \\
\hline GB width & & & 4.0 & \\
\hline Male & $1.65 \pm 0.58$ & 1.0 & 1.0 & \\
\hline Female & $2.02 \pm 0.86$ & & & \\
\hline
\end{tabular}

Table-II. Distribution of the patients according to Age, GB length and width $(n=87)$

\begin{tabular}{|c|c|c|c|c|c|c|c|}
\hline \multirow{2}{*}{ GB Length } & \multicolumn{6}{|c|}{ Epithelial Lining (Microscopic Finding) } & \multirow{2}{*}{ P-Value } \\
\hline & Abnormal & Dysplasia & Fibrosis & Inflamed & Hyperplasia & Normal & \\
\hline $1-3$ & 2 & 0 & 3 & 0 & 0 & 2 & \multirow{4}{*}{0.001} \\
\hline $4-6$ & 1 & 1 & 21 & 2 & 2 & 29 & \\
\hline $7-9$ & 0 & 0 & 17 & 2 & 0 & 5 & \\
\hline Total & 3 & 1 & 41 & 4 & 2 & 36 & \\
\hline \multicolumn{8}{|c|}{ No. of Gall Stones } \\
\hline Multiple & 2 & 1 & 32 & 3 & 2 & 27 & \multirow{3}{*}{0.048} \\
\hline Single & 1 & 0 & 9 & 1 & 0 & 9 & \\
\hline Total & 3 & 1 & 41 & 4 & 2 & 36 & \\
\hline \multicolumn{8}{|c|}{ Serosal Surfac } \\
\hline Normal & 3 & 0 & 27 & 4 & 0 & 28 & \multirow{3}{*}{0.26} \\
\hline Thickened & 0 & 1 & 14 & 0 & 2 & 8 & \\
\hline Total & 3 & 1 & 41 & 4 & 2 & 36 & \\
\hline \multicolumn{8}{|c|}{ Mucosa } \\
\hline Atrophic & 0 & 0 & 7 & 0 & 0 & 3 & \multirow{5}{*}{.002} \\
\hline Hemorrhagic & 0 & 1 & 20 & 0 & 1 & 0 & \\
\hline Normal & 3 & 0 & 14 & 4 & 1 & 29 & \\
\hline Nodular & 0 & 0 & 0 & 0 & 0 & 4 & \\
\hline Total & 3 & 1 & 41 & 4 & 2 & 36 & \\
\hline
\end{tabular}

Table-III. Comparison of GB length, gall stone, serosal surface, external mucosa and Microscopic findings $(n=87)$

\section{DISCUSSION}

Cholelithiasis is a most common bile tractal disorder, causing a number of pathological changes in the epithelium including metaplasia and hyperplasia that could be the precursor of gallbladder cancer lesions. ${ }^{13,14}$

This pathogenesis is mainly because of chronic irritation and chemical lesions in the gallbladder mucosa. ${ }^{15}$ Such changes in the gallbladder wall can even begin before the stone formation. ${ }^{16}$

Altering the composition of the bile as a result of oxidative stress and the effects of oxygen-free radicals on the mucosal gallbladder, may result in altered bile absorption and concentration with saturation, followed by stone formation. ${ }^{16}$

During my research we attempted to assess and correlate these modifications with internal mucosal findings and various calculations for historical modifications in the gallbladder mucosa in gallstone patients. Many modifications have been discovered such as hyperplasia, dysplasia and fibrosis; many calculations and big gallbladder duration have been considerably affected. Figure-1

We discovered a median age of $38,80 \pm 8,92$ years in our research. Females were discovered in a total of $65(74.7 \%)$, while males were discovered to be $22(25.3 \%)$. 


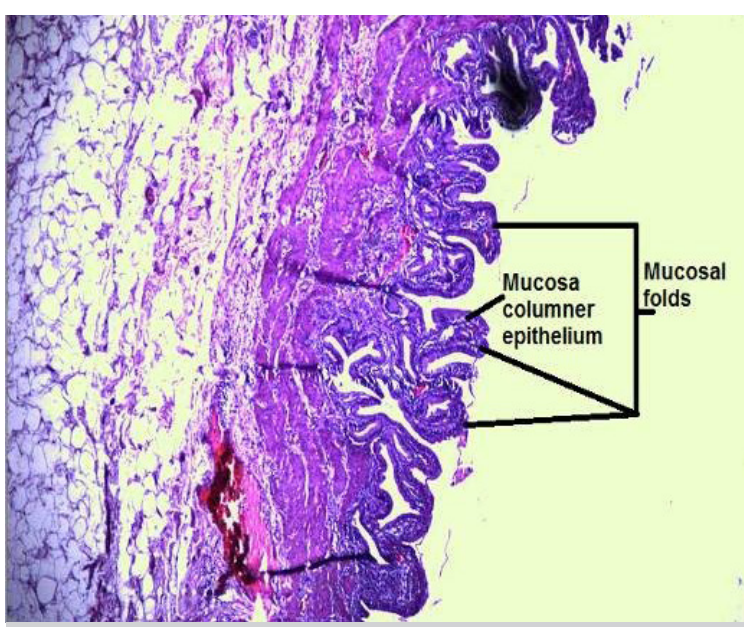

A.Normal gall Bladder (GB)Mucosa Columner epithelium with Mucosal Folds and villi (three layers) (10 HPF)

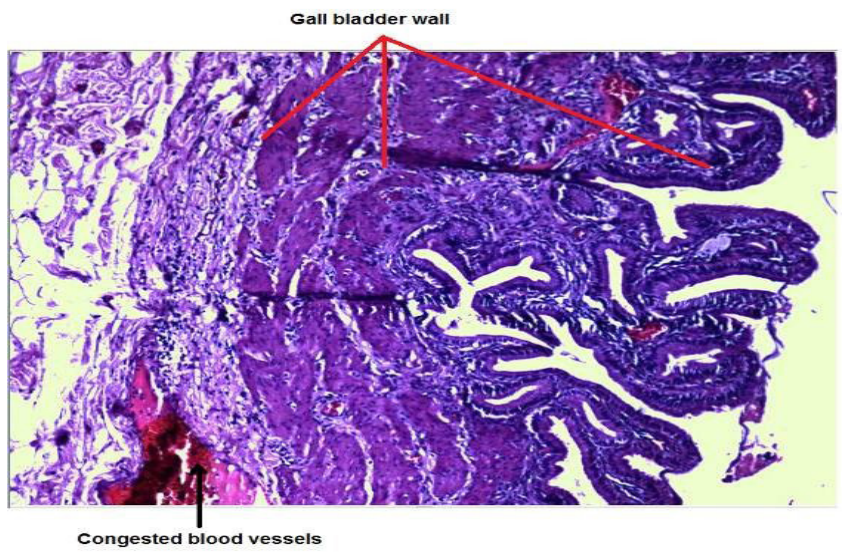

C.GB wall completely inflamed from Mucosa to Serosa showing congested blood vessels. (10 HPF)

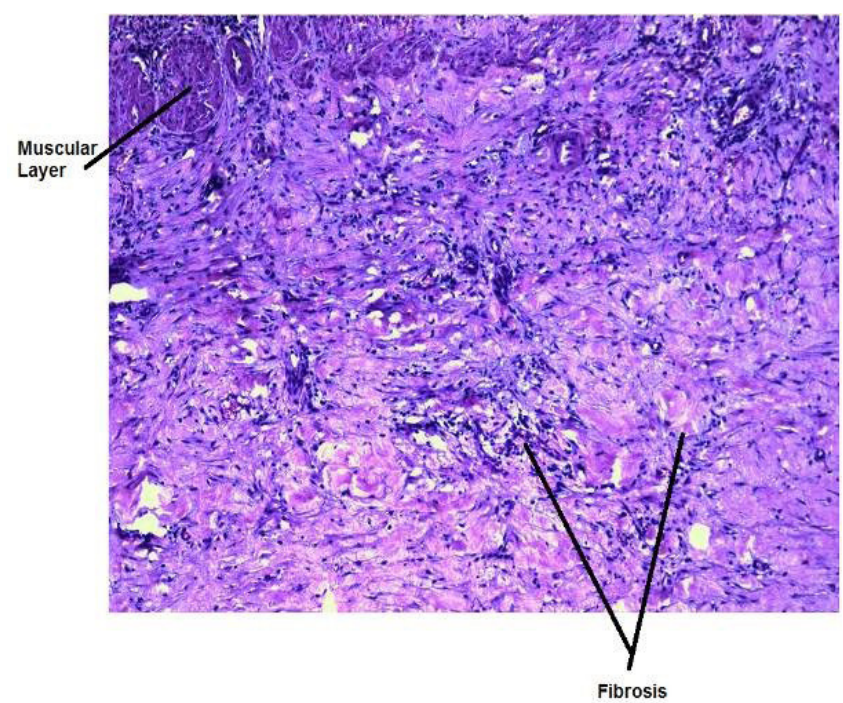

E.GB wall showing muscular layer and serosa thickened due to fibrosis. (10 HPF)

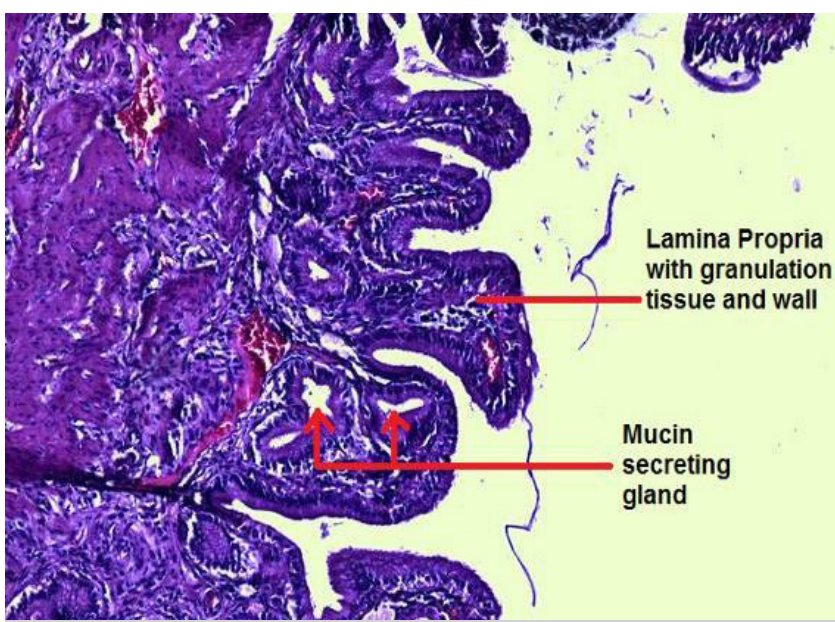

B.Lamina Propria showing granulation tissue and wall shows normal mucin secreting gland. (10 HPF)

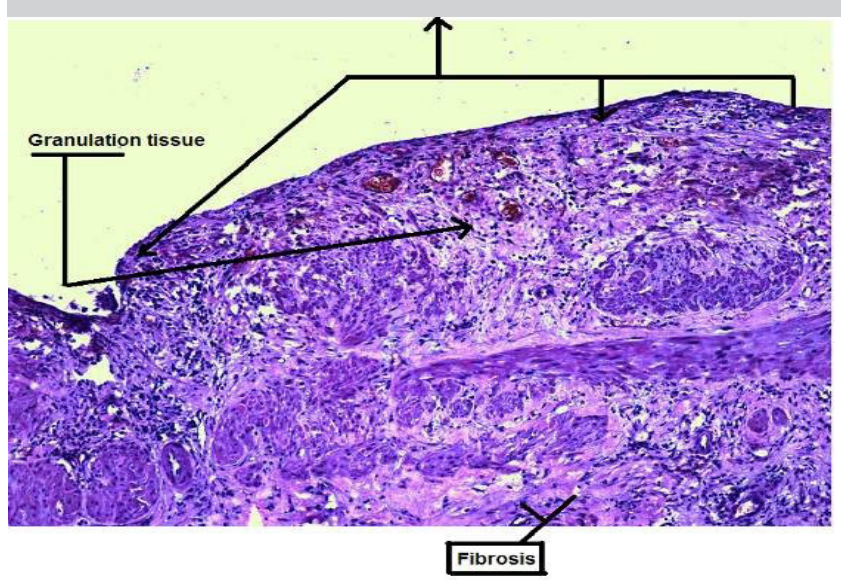

D.GB wall showing loss ofimucosal folds and mucosa is ulcerated showing granulation tissue with fibrosis and hickened. (10 HPF)

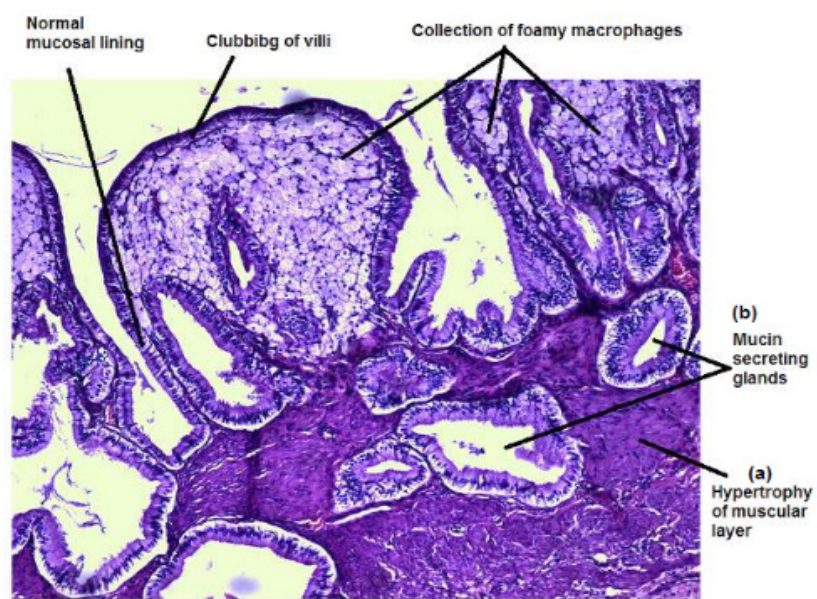

F.10.Gall bladder wall showing all layers: Mucosa shows clubbing of villi, normal mucosal lining is intact, lamina propria shows aggregation of foamy macrophages (containing cholesterol) 

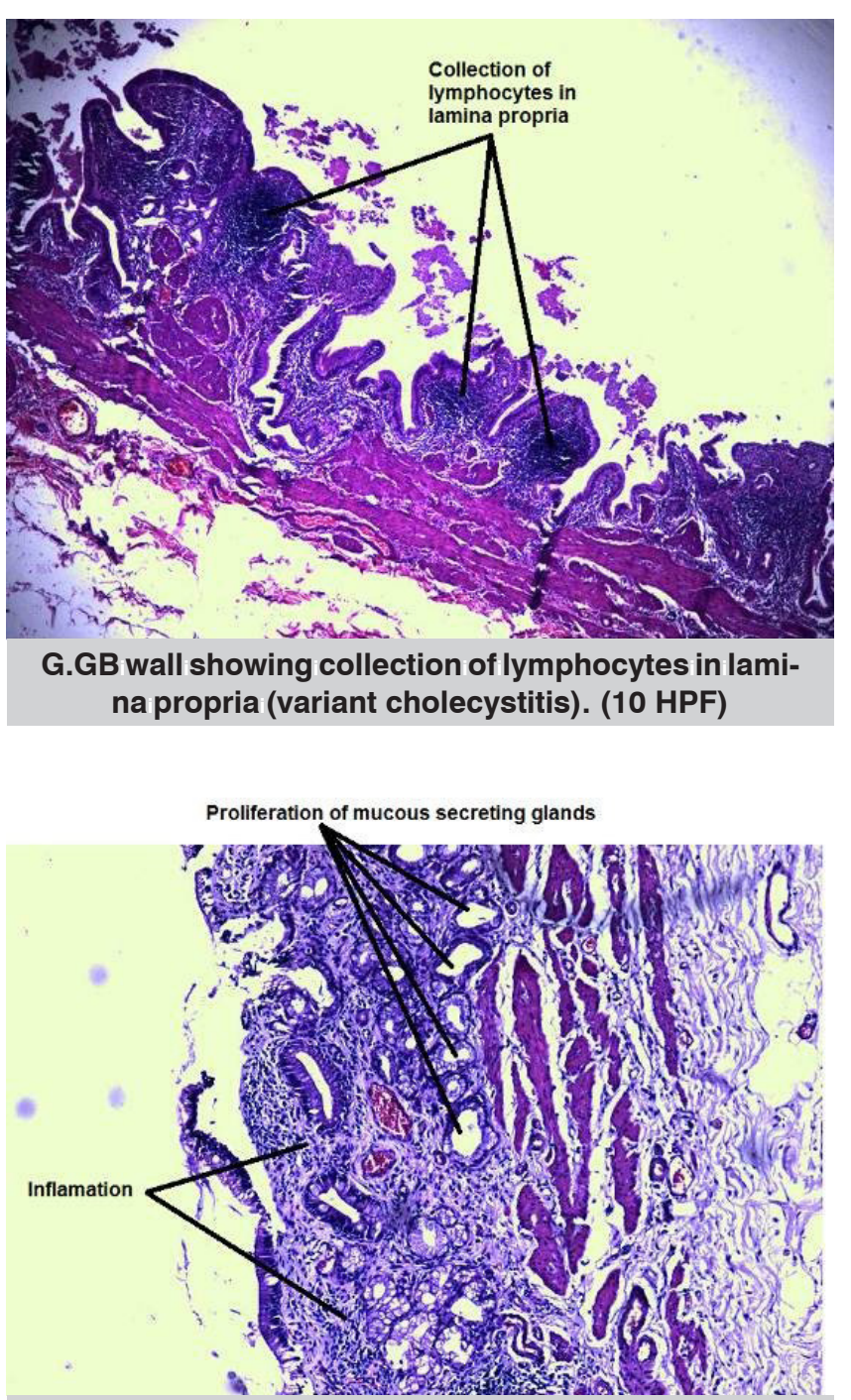

I.GB Wall + Inflammation with proliferation of mucous secreting glands (chronic cholecystitis glandularis). (10 HPF)

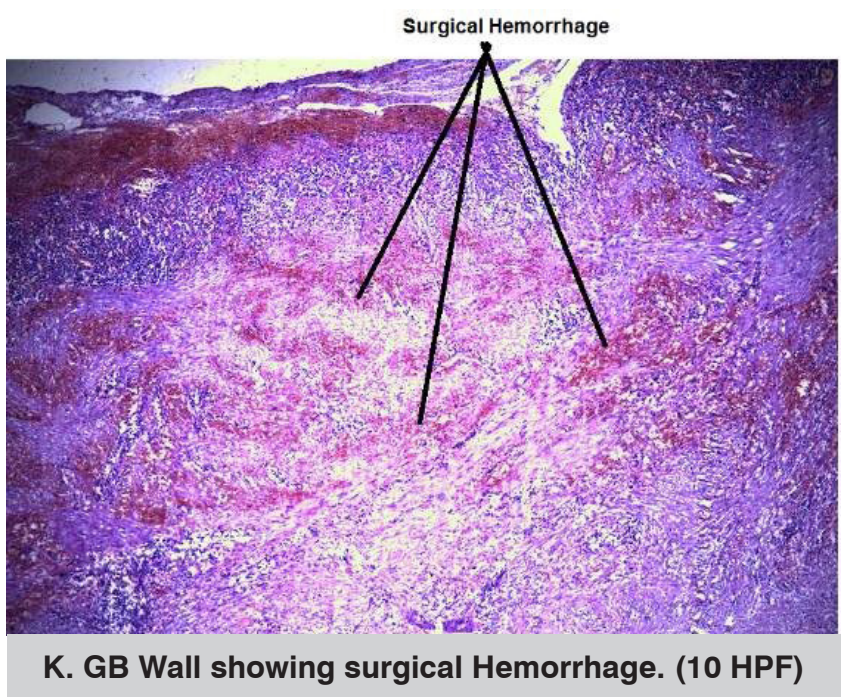

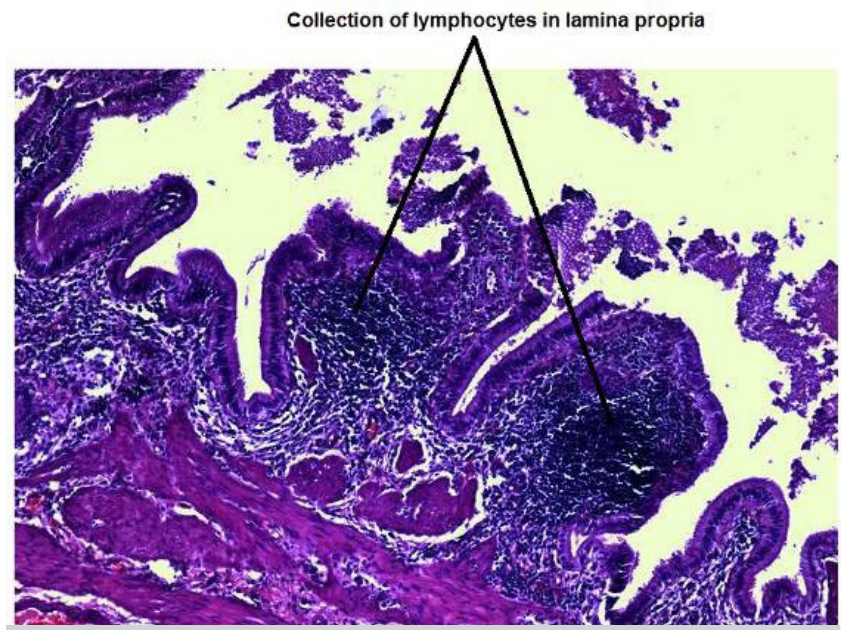

H. Follicular cholecystitis. (10 HPF)

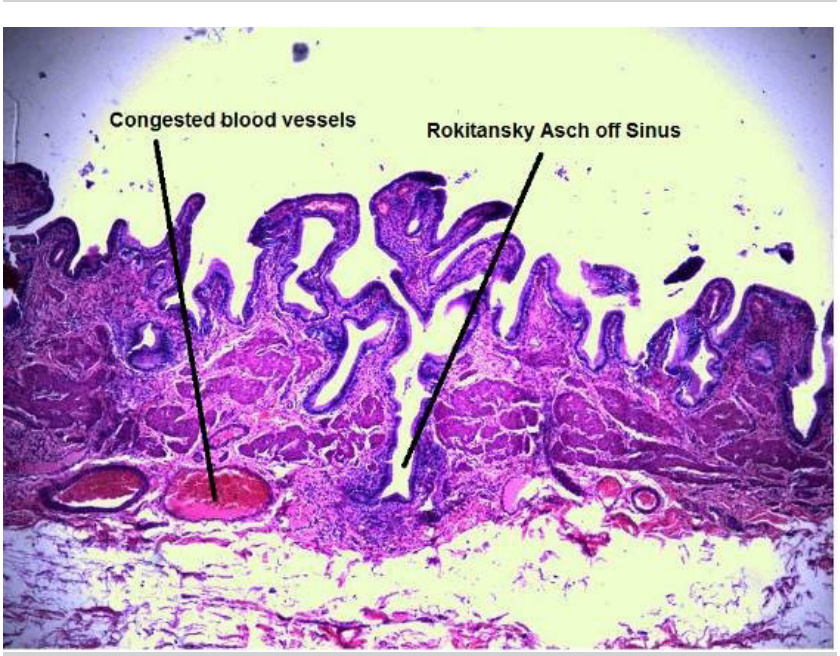

J.GB wall mucosa showing a sinus extending from mucosa up to serosa (rokitansky aschoffisinus) scrosa showing congested blood vessels. (10 HPF)

Soomro AG et el ${ }^{10}$ have also recorded an average age of 47 years for patients with cholecystectomy.

However, in their survey Gelani et al and Tyagi et al ${ }^{17}$ revealed average age 42.7 and 43.6 years.

Khan $\mathrm{R}$ et al. ${ }^{9}$ reported that The number of female and 24 male of 140 gallbladder specimens was 116 (M: F ratio 1: 4.8). The patients ' median age was 42,5 (22-70 years). 20 gall bladder (14.5 percent) and 120 single stone (85.5 percent) were found in single stone.

Baig SJ et al ${ }^{8} 29$ of 40 patients have been revealed to be women and eleven to be men. Our patients' average age was $38+21$ years. 
In our research, 29(33.3 percent) people were congested in serosal soil while in 58 (66.7 percent) it was usual; for 10(11.5 percent), for 22(25.3 percent) the mucosa was normal and for 51 (58.6 percent), for 4(4.6 percent), the nodular surface was normally congested.

Khan $\mathrm{R}$ et $\mathrm{al}^{111}$ reported that the gallbladder serosal surface has been found to be normal in $100(71.5 \%)$ and congested in $40(28.5 \%)$ patents. The thickness of gall bladder wall in 80 (57.5\%) and in 60 patients (42.5\%) was normal $(<3 \%)$ and thickened (> $3 \%$ ).

In 50 (35.5\%), hemorrhagic (7.5\%), strawberrylike $(7.5 \%)$ and $50(35.5 \%)$, and slightly nodular (14\%), mucosa was normal. Mucosa was hemorrhages in 10 (7.5\%). In addition, Khan R et al. ${ }^{9}$

Mented that the congestion and thickness of the gallbladder wall was more in symptom patients, but in both symptomatic and asymptomatic gallbladder the mucosal burden was similar

In this set of microscopic results, 36(41.3\%) patients had ordinary results, $41(47.1 \%)$ of patients had fibrosis most commonly, and in $1,1(1.1 \%)$ births $1(1.1 \%), 3.4 \%$ was inflamed and $2.3 \%$ were affected by hyperplasia. Similar results were also observed in the research. Khan $R$ et $a^{111}$ as: 13 specimens (9\%) showed normal epithelium. The following epithelial hylindrical conditions have been observed: 83 (69\%), 23 (16.5\%), 22 (15.5\%), 12 (8.5\%) and in situ, in 1 $(0.7 \%)$ of the specimens.

In 26 samples (19 percent), fibrosis and ulceration were discovered. Of 83 epithelial hyperplasiarelated samples, 13 (16\%) contained antral metaplasia, 16 (19\%) intestinal metaplasia, and 5 (6\%) contained dysplasia.

111 Three (4\%) individuals had antral and gut metaplasia with hyperplasia and 1 (1\%) had hyperplasia with both metaplasias and dysplasia

Various grading and different phases of parietal fibrosis (staging) were most often present at microscopic muco lesions. Yol S et $\mathrm{al}^{18}$ said that greater levels of organ fibrosis as compared with females were observed in males and a greater amount of inflammatory cells.

Another research has shown that morphological lesions in cholelithiasis, primarily in the mucosa, are correlated. Csendes A et al 19 stated that histological lesions in the gallbladder were proposed to be associated with advanced era and were primarily present in women. Baig et al. ${ }^{8}$

In only 50 percent of patients with colelithiasis "pure" acute colecystitis was identified. In 21 instances epithelial hyperplasia with disturbance has been recorded by Gopalakrishnan $\mathrm{M}$ et al. ${ }^{20}$

In reaction to acute discomfort, Putz and Willens et al ${ }^{21}$ suggest that cholelithiasis induces effective development of the epithel.

A tiny amount of hyperplasias, according to Albores Saavedra et $\mathrm{al}^{22}$, develop into atypical hyperplasia, which develops into institute carcinoma and lastly in invasive carcinoma. Muna Zahir et.al discovered similar results in the research. ${ }^{14}$

Khan $\mathrm{R}$ et $\mathrm{al}^{9}$ It demonstrates considerably, depending on figures or size of the gallstones in histological modifications. Martinez et al. ${ }^{23}$ also had similar outcomes, who could not show a link between gallstone form and scores to modifications in the gallbladder epithelial.

In addition, the above-mentioned histological variations in bile blocks with cholesterol crystals have been clearer because their bigger size has caused greater discomfort to the gallic bladder mucosa. Figure-1 Muna Zuhair et $\mathrm{al}^{14}$ as well as the toxic effect of lactogenic bile, which causes chemical injuries to the mucosa in lower pigment stones, and causes a less acute response.

One of the only significant features of pigment rocks was that mucosal bubbles were not present with the flattening of the ground epithel and gallbladder thickening. 
Gallstones are the world's most common cause of malignancy. Gallstones in the gall bladder contribute to a number of histological shifts. Some of them might predict malignant lesions. The high rates of gallstone disease in women contribute largely to the number of pregnancies.

The most likely cause of the increased risk is gender hormones. Estrogen enhances the release of biliary cholesterol triggering extreme concentration of bile cholesterol.

Therefore, hormone replacement therapy has been identified in postmenopausal women as an increasing risk of gallstone disease.

Even after an intraoperative analysis of the cholecystectomy samples, early-stage tumors for which surgical resection is most effective remain difficult to diagnose pre-operatorally.

One of the worst cancer deaths is histological alteration. It is often the fundamental pathology of chronic cholecystitis with cholelithiasis in individuals who undergo surgery;

The etiological function of longstanding chronic gallstones inflammation in histological variability is regarded an significant one. Fibrosis, dysplasia, swelling and hyperplasia were more frequent in histological gallbladder alterations connected with gallstones

In the most tertiary hospitals in Pakistan, including the primary investigator's own organization, the practice of discarding gall bladder specimens is normal on the pretext that "chirurgen best understands which gall bladder is sent to laboratory."

Only those samples that display serious defects are limited to histopathology. These practices are supposed to be always associated with macroscopic abnormalities with gallbladder carcinoma.

This selective strategy is at the same moment justified by claiming that it lowers the economic liabilities of the patient and the workload of the pathologist.

This goes against the global custom of sampling gallbladder to be sent constantly for histological analysis solely for the purpose of early identification of discreet carcinomas.

\section{CONCLUSION}

We concluded that hemorrhagic and fibrosis changes were the most common mucosal findings, and significantly associated with multiple calculus cholelithiasis. Cholelithiasis can produce many histo-morphological changes in the gallbladder mucosa, which could be precursor lesion of gallbladder carcinoma. Cases with presentation of multiple calculi, having great risk of hyperplasia.

Copyright@ 03 Dec, 2019.

\section{REFERENCES}

1. Bansal A, Akhtar M BA. A clinical study: Prevalence and management of cholelithiasis. Int Surg J. 2016; 10(3):134-139.

2. Pani DJ. Histological changes in human gallbladder in pathological condition including cholecystitis and cholelithiasis an analytical study. IOSR J Pharm. 2013; 3(4):01-13. doi:10.9790/3013-034301-13.

3. Pradhan SB, Joshi MR, Vaidya A. Prevalence of different types of gallstone in the patients with cholelithiasis at Kathmandu Medical College, Nepal. Kathmandu university medical journal. 2009;7(3):26871.

4. Stinton LM, Shaffer EA. Epidemiology of gallbladder disease: Cholelithiasis and cancer. Gut Liver. 2012;6(2):172-187. doi:10.5009/gnl. 2012.6.2.172.

5. A. Channa $\mathrm{N}$, Khand $\mathrm{F}$, Bhanger $\mathrm{M}, \mathrm{H}$ Leghari $\mathrm{M}$. Surgical incidence of Cholelithiasis in Hyderabad and adjoining areas (Pakistan). Pak $J$ Med Sci. 2004;20.

6. Khand FD. Cholelithiasis in Southern Sindh (Pakistan): Incidence and composition of gallstones. Specialist. 1997; 13:263 - 70.

7. Samra ZQ, Ikram N, Parveen $R$, Khan AM AM. Composition of gallstones of patients of Multan region. Sci J Pure Appl. 1988; 7(1):1-9.

8. Baig SJ, Biswas S, Das S, Basu K, Chattopadhyay G. Histopathological changes in gallbladder mucosa in cholelithiasis: Correlation with chemical composition of gallstones. Trop Gastroenterol. 2002; 23(1):25-27. 
9. Khanna R, Chansuria R, Kumar M, Shukla HS. Histological changes in gallbladder due to stone disease. Indian J surg. 2006 Aug 1;68(4):201-4.

10. Soomro AG, Jarwar M, Ali SA, Nizamani NB, Memon AS. Frequency of Carcinoma in Gall Bladder Specimens sent for Histopathology in a University Hospital. JLUMHS. 2013 Jan;12(01):55.

11. Kasprzak A, Malkowski W, Biczysko W, Seraszek A, Sterzyńska K, Zabel M. Histological alterations of gallbladder mucosa and selected clinical data in young patients with symptomatic gallstones. $\mathrm{Pol} J$ Pathol. 2011; 62(1):41-49.

12. Dooley JS, Gurusamy KS, Davidson BR. Gallstones and benign biliary disease. In: Sherlock's Diseases of the Liver and Biliary System. Chichester, UK: John Wiley \& Sons, Ltd; 2018:256-293. doi:10.1002/9781119237662. ch14.

13. Elfving E, Silvonen E TH. Mucosal hyperplasia of the gallbladder in cases of cholelithiasis. 1999;135:519522.

14. MunaZahair, RanaMumtaz K. Histological changes of gallbladder mucosa: Correlation with various types of cholelithiasis. Iraqi J Comm. 2011; 24(3):234-240.

15. Rubin E, Farber J. The gallbladder and extra hepatic bile ducts: In Pathology Lippincott-Williams \& Wilkins. In: Philadelphia. 3rd ed. ; 1999:830-838.

16. Chang HJ, Suh JI KS. Gallstone formation and gallbladder mucosal changes in mice fed a lithogenic diet. J Korean Med Sci. 1999; 14:286-292.
17. Gilani SI, Ali I, Raza W, Hassan A, Qureshi I. Histopathological evaluation of cholecystectomy specimens: an experience from Holy Family Hospital, Rawalpindi. Pak J Gastrol. 2008 Mar;22(1):15-9.

18. Yol S, Kartal A, Vatansev C, Aksoy F, Toy H. Sex as a factor in conversion from laparoscopic cholecystectomy to open surgery. JSLS: Journal of the Society of Laparoendoscopic Surgeons. 2006 Jul;10(3):359-63.

19. Csendes A, Smok G, Burdiles P, Diaz JC, Maluenda $\mathrm{F}$, Korn $\mathrm{O}$. Histological findings of gallbladder mucosa in 95 control subjects and 80 patients with asymptomatic gallstones. Dig Dis Sci. 1998; 43(5):931934. doi:10.1023/A:1018897827285.

20. Gopalakrishnan M, Thilagavathy S, Kamaleshwari J, Shifa R. Morphological spectrum of changes in gall bladder in correlation to various types of gallstones: a study of 100 cases. Annals of Applied Bio-Sciences. 2016 Jun 15;3(2):A196-202.

21. Putz P, Willems G. Cell proliferation in the human gallbladder epithelium: Effect of distension. Gut. 1979;20(3):246-248. doi:10.1136/gut.20.3.246

22. Albores-Saavedra J, Molberg K, Henson DE. Unusual malignant epithelial tumors of the gallbladder. Semin Diagn Pathol. 1996; 13(4):326-338.

23. Martínez Guzmán G, de la Rosa Bayón J. Neoplasias y displasias de vesícula biliar y su relación con litiasis. Estudio clinicopatológico de casos y controles. Rev. gastroenterol. Méx. 1998 Jun;63(2):82-88.

\begin{tabular}{|c|c|c|c|}
\hline \multicolumn{2}{|c}{ AUTHORSHIP } & AND CONTRIBUTION DECLARATION \\
\hline Sr. \# & Author(s) Full Name & \multicolumn{1}{|c|}{ Contribution to the paper } \\
\hline 1 & Shamshad Bano & $\begin{array}{l}\text { Collected the data, did the literature search, } \\
\text { drafted the manuscript, assisted in writing the } \\
\text { paper. } \\
\text { Designed the research, assessed the vases, } \\
\text { wrote the paper, interpretation of discussion } \\
\text { and data entry in SPSS. } \\
\text { Involved in data collection, analyzed the data } \\
\text { revised the manuscript. } \\
\text { Revised the original manuscript, reviewed } \\
\text { the cases, analyzed the data and assisted } \\
\text { in writing the paper, interpretation in result } \\
\text { writing. } \\
\text { References, citation manager \& designing of } \\
\text { results and charts and Graphs in manuscript. } \\
\text { Data entry in SPSS and other technical help, } \\
\text { help in correction. }\end{array}$ \\
\hline 5 & Lal Bakhsh & Gulshad Wagan & Asad Ali Zardari \\
\hline
\end{tabular}

